\title{
O HOMEM MODERNO E O DIREITO: HOMEM PRIMITIVO DA SOCIEDADE MODERNA OU HOMEM CIVILIZADO DA SOCIEDADE PRIMITIVA?
}

\author{
Cynthia Pereira de Araújo ${ }^{1}$
}

\section{Resumo}

Este trabalho visa precipuamente a análise das razões que levam importantes estudiosos do homem primitivo a concluírem pela ausência de consciência do "eu" em sua mentalidade. A compreensão do funcionamento da mente do homem primitivo permite entender seus reflexos sobre o Direito, com o que se busca a percepção de como a temática proposta pode auxiliar um melhor entendimento acerca do homem em si, notadamente o homem civilizado. Os estudos baseiam-se, principalmente, em narrativas reais decorrentes de pesquisas de campo realizadas por etnólogos e antropólogos, sob a ótica sociológica e jurídica de importantes autores, especialmente Hans Kelsen (Society and Nature). Estas pesquisas foram realizadas em tribos atuais que não se civilizaram, mantendo intactas as características de suas origens. Como restará demonstrado, apesar da base empírica, as conclusões alcançadas neste trabalho melhor adéquam-se aos homens primitivos anteriores a qualquer civilização, os quais não tiveram oportunidades provenientes da transmissão de conhecimento perpetuada desde as primeiras gerações. Esses estudos resultaram na constatação já exarada por Wilson Wallis de que se o primitivo é potencialmente um homem civilizado, o civilizado é potencialmente um primitivo. Tal afirmação é possível diante da inexistência de diferenças ontológicas entre a mente do homem primitivo e a do homem civilizado, premissa que permeou todo este trabalho e que foi comprovada por relações argumentativas lógicas. Concluiu-se, no entanto, que a inexistência deste dualismo absoluto não impede que homem primitivo e homem civilizado tenham formas diversas de perceber o mundo e processar informações já absorvidas por eles de maneiras distintas. São, aliás, essas considerações que permitem importantes revelações que vinculam o primitivismo à potencial civilidade.

Palavras-Chave: homem primitivo, homem moderno, Direito, Kelsen.

\section{INTRODUÇÃO}

Este trabalho tem como tema central a ausência de consciência do "eu" na mente do homem primitivo, suas repercussões no direito (ou no modo do homem primitivo ver o direito), bem como no homem moderno e em sua visão sobre o direito. Essa temática, embora raramente estudada, pode a nosso ver auxiliar a compreensão de vários fenômenos sociais atuais que têm repercussões jurídicas.

Como demonstra Kelsen, os primitivos não têm experiência de individualidade, percebendo sua existência apenas enquanto parte de um todo, e não autonomamente (KELSEN, 1946). Nosso estudo parte da premissa de que inexistem diferenças ontológicas entre a mente do homem primitivo e a mente do homem civilizado, a despeito de terem estes formas diversas de perceber a realidade e processar informações. Admitimos que a

\footnotetext{
1 Bacharel em Direito pela Universidade Federal de Minas Gerais (2007). Mestranda em Teoria do Direito na
} PUC/MG. Advogada da União lotada na Procuradoria da União no Estado de Minas Gerais.

Revista da Faculdade Mineira de Direito, v.13, n. 25, jan./jun. 2010 - ISSN 1808-9429. 
consciência do homem sobre sua individualidade e sobre sua relação com os outros seres depende não só da capacidade potencial de inteligência, mas também do grau de desenvolvimento de seus pensamentos, de seu interesse pelos objetos de conhecimento e de sua necessidade em estabelecer conexões entre os fatos.

Observa-se que a ausência de consciência do "eu" dos primitivos é reflexo do seu modo de perceber o mundo, preponderantemente emocional e imerso em um forte espírito de grupo já arraigado, o que retarda o discernimento entre homens e entes não humanos, determinando a inexistência de individualidade.

A ausência de "ego-consciousness", como a denominou Kelsen (KELSEN, 1946, p. 6), demonstra que o estágio de desenvolvimento da mente do homem primitivo é precário. $\mathrm{O}$ instinto, muito mais que a razão, impulsiona-o. É verdade, entretanto, que esse tipo de comportamento, se não é do homem civilizado característica dominante, também não lhe é estranho.

Não é possível instituir um dualismo absoluto entre o homem primitivo e o homem civilizado. No comportamento habitual do homem primitivo há traços típicos do homem civilizado, o que não assusta, já que o primitivo desencadeia a civilização. Mas há, no comportamento eventual do homem civilizado, atitudes díspares da evolução e fundamentalmente primitivas.

A análise da mente primitiva abre caminhos pouco percorridos para que se entenda bem o homem. Não se trata de simples revelações interessantes sobre costumes excêntricos. Conforme explica Malinowski, "há certos aspectos da antropologia de verdadeiro caráter científico que não nos levam do fato empírico para o reino da conjectura sem controle, mas ampliam o conhecimento da natureza humana e propiciam uma aplicação prática direta" (MALINOWSKI, 2003, p. 9).

É mister esclarecer, todavia, que a finalidade precípua deste trabalho não é o pragmatismo. Arriscam-se, todavia, reflexões sobre a natureza humana, no que evolui e no que parece estagnar.

Como ensina Febvre, os grupos humanos sentem necessidade de buscar no passado os fatos, acontecimentos e tendências que preparam o tempo presente e permitem compreendêlo, ajudam a vivê-lo (CHESNEAUX, 1995, p. 23). Para Chesneaux, "esse passado, próximo ou longínquo, tem sempre um sentido para nós. Ele nos ajuda a compreender melhor a sociedade na qual vivemos hoje, a saber o que defender e preservar, saber também o que mudar e destruir" (CHESNEAUX, 1995, p. 22). É, preciso, no entanto, como afirma Samuel, 
assumir que "por mais zelosamente que protejamos a integridade do nosso tema de estudo, não podemos isolá-lo de nós mesmos” (Apud FONTANA, 1998, p. 267).

\section{A AUSÊNCIA DA CONSCIÊNCIA DO EU NO HOMEM PRIMITIVO}

\subsection{O homem primitivo}

O significado da expressão "homem primitivo", na linguagem coloquial, é o de homem "contemporâneo dos primeiros tempos de uma civilização, colonização, história" ou "existente nos primeiros tempos da Terra, anterior a qualquer civilização, e a tudo quanto pareça próprio desses tempos" (HOUAISS, 2001, p. 2298).

Impõe-se que façamos um paralelo entre o homem primitivo "primeiro habitante da Terra" e o homem que pertence a tribos atuais que não se civilizaram, mantendo as características de suas origens e evitando a "contaminação" pela civilização. Trata-se de um tema pouco explorado, pelo que tomamos o cuidado de abordar sem a pretensão de que propor uma teoria científica.

É sabido que as fontes de estudo sobre o comportamento dos homens primitivos são, em sua maioria, decorrentes de análises práticas em tribos atuais. Mas não se pode pretender que os homens primitivos de outrora tenham tido as mesmas oportunidades de aprendizado e conhecimento que os homens que vivem atualmente isolados da civilização. Deve-se pensar que os homens de hoje, vivam ou não de forma "primitiva", são antecedidos por inúmeras gerações, as quais transmitiram informações que interferem em seu modo de ver o mundo.

Não se questionam memória genética ou aspectos psicológicos ou mesmo biológicos da mente humana. Trata-se de visualização prática de transferência de conhecimento. Se o homem pode buscar nas gerações anteriores dados de que invariavelmente necessita, fundamentais à vida, em vez de aprendê-los contando apenas com a sua vivência, parte de um ponto mais avançado na bagagem de aprendizado que poderá acumular durante sua existência. Quanto maior o número de gerações precedentes a um indivíduo, maior sua possibilidade de acesso a conhecimentos prévios essenciais à garantia de sua sobrevivência, visto que, já os tendo, não precisa buscá-los na própria experiência. Pode, então, desenvolvê-los e transmitilos a seus herdeiros de forma mais avançada do que recebeu, para que o façam continuamente.

Diante dessas considerações, destacamos que os argumentos levantados em nosso trabalho melhor se adéquam aos homens primitivos "anteriores a qualquer civilização". 


\subsection{A ausência de individualidade}

O homem primitivo não tem "ego-consciousness". A ausência de consciência do "eu" pode ser encarada sob dois enfoques: o primeiro, pressuposto do segundo, diz respeito ao que poderíamos chamar de carência de percepção de "humanidade" sob o sentido de "seres humanos", criaturas diversas de todos os outros seres e coisas; o segundo refere-se à falta da própria individualidade, a qual personaliza um homem ante os demais.

Sob o primeiro enfoque, a ausência de consciência do "eu" decorre da maneira coordenada ou subordinada como se dá a relação entre o homem primitivo e o meio em que vive. O homem primitivo se percebe em condição de igualdade ou inferioridade perante animais irracionais, plantas, pedras, instrumentos de trabalho e outros objetos com os quais coexiste. Como explica Kelsen, "os etnólogos concordam que o homem primitivo, ao contrário do civilizado, não se considera o 'Senhor da Criação', superior aos outros animais, às plantas e aos objetos inanimados, mas igual ou mesmo inferior a eles, tratando-nos com respeito e medo" (KELSEN, 1946, p. 6-7) ${ }^{2}$.

Ao se equiparar aos animais, às plantas e aos objetos inanimados (coordenação), impedindo-se de compreender suas peculiaridades e sua capacidade de modificação da natureza, o homem primitivo faz patente sua ausência de consciência do "eu". A homogeneidade que imagina existir tem sentido na exata proporção do desconhecimento de sua individualidade. Não fosse sua ignorância sobre o que o distancia ontologicamente dos "seres" diversos que com ele convivem, não haveria de vê-los como semelhantes.

Não se exige maior esforço intelectual para que se percebam as diferenças entre os homens e os demais seres e objetos. Todavia, aos homens primitivos, o aspecto mais relevante dessa diferenciação - a racionalidade - está deslocado a segundo plano, prevalecendo o fluxo emocional. Como afirma Kelsen, a consciência do homem primitivo é essencialmente caracterizada pela prevalência do componente emocional sobre o racional, havendo aquele, na verdade, dominado sua mente em sua quase integralidade (KELSEN, 1946, p. 8).

A auto-inferiorização (subordinação) do primitivo em face dos demais entes leva às mesmas conclusões de modo ainda mais determinante. Ao se deparar com seres visivelmente maiores, mais fortes ou vigorosos, a atenção do primitivo se dá diretamente ao aspecto físico,

2 Tradução livre para o português do texto original em inglês: "Ethnologists agree in their reports that primitive man, in contradistinction to civilized man, does not consider himself as Lord of Creation, superior to animals, plants, and inanimate objects, but as equal, if not sometimes even inferior, treating these other beings and objects with respect and awe".

Revista da Faculdade Mineira de Direito, v.13, n. 25, jan./jun. 2010 - ISSN 1808-9429. 
visto que não é ainda capaz de perceber a diferença entre a sua potencialidade de inteligência e a performance meramente instintiva dos animais.

Apontam os estudos antropológicos que, muitas vezes, o homem primitivo atribui o mérito pelo produto de seu trabalho de construção ou de emprego de um instrumento ao próprio instrumento, e não a si enquanto manipulador deste: "ele considera seu instrumento um deus, enquanto o homem civilizado às vezes vai tão longe a ponto de reconhecer que até mesmo Deus é somente um instrumento do homem" (KELSEN, 1946, p. 8) ${ }^{3}$.

O segundo enfoque da ausência de consciência do "eu" é inferência lógica e necessária da conclusão - exaustivamente provada - de que o homem primitivo não consegue se diferenciar sequer de entes não humanos. Em face dessa premissa, é inconcebível supor que lhe fosse possível avaliar-se perante os demais homens, encontrando dessemelhanças suficientes a determinar personalidades diversas e a caracterizar a individualidade de cada um.

É importante notar que as diferenças entre homens e seres não humanos são insofismáveis, visíveis, físicas, de percepção indizivelmente mais simples que as disparidades entre os homens, muitas vezes mais intrínsecas que exteriores. Se era ao homem primitivo impraticável notar as diferenças entre homens e pedras ou animais, diferenciar-se de seus semelhantes seria obviamente impensável, já que não se havia ainda alcançado nem mesmo o pressuposto para a descoberta da individualidade, o dito aspecto de "humanidade".

O homem primitivo é incapaz de se reconhecer no mundo a ponto de observar seu comportamento a partir dos atos de seus companheiros. O primitivo percebe a sociedade do ponto de vista do outro, praticando a "tu-analogy", no lugar da "ego-analogy" (KELSEN, 1946, p. 29-30). Suas atitudes e até reações são apreendidas por assistir às de seus semelhantes. Sua individualidade é tão remota que, antes de se intuir no mundo, notou outro homem. E, destaque-se, esse outro homem é tão-somente parte da natureza, do meio em que vive. Não se trata de compreender as diferenças que determinam ente diverso. Até seria possível conceber que a passagem do homem primitivo para a compreensão sobre a individualidade houvesse sido viabilizada pela percepção do outro homem e, finalmente, de si mesmo, como semelhante daquele. No entanto, no momento em que a individualidade inexiste, o outro homem é apenas outro ser qualquer, como animais e pedras

3 Tradução livre para o português do texto original em inglês: "He considers his instrument a god, whereas civilized man sometimes goes so far as to recognize that even God is only an instrument of man". 


\section{A MENTE DO HOMEM PRIMITIVO}

\subsection{Princípio da causalidade}

A idéia de que os eventos são determinados pelas leis da natureza sob o princípio da causalidade, base fundamental do pensamento científico, está inteiramente fora do alcance do homem primitivo (KELSEN, 1946, p. 3).

Kelsen alerta que até poder-se-ia falar em "pensamento causal" no caso em que a regularidade percebida em uma sucessão de eventos é também considerada necessária. Entretanto, o fator determinante para que se pudesse atribuir ao primitivo a tendência ao pensamento causal não acontece. Essa cadeia regular de eventos pela qual se guia, eventualmente, a conduta do homem primitivo, não se lhe apresenta como qualquer causa de meditação (KELSEN, 1946, p. 3). Ou seja, ainda quando percebe a ligação entre um evento e outro, não estabelece qualquer relação de caráter cognitivo.

Mais do que isso, é absolutamente comum o homem primitivo depreender relação de fatos completamente independentes, a ponto de se deduzir que, quando o faz quanto a situações realmente conectadas, trata-se de mera coincidência.

A lei da causalidade somente pode surgir se há reflexão consciente. Esta ocorre na mente do homem primitivo apenas se acontecem coisas extraordinárias, que interrompem a sucessão normal dos eventos, e, principalmente, se fortes emoções são despertadas. Ainda que rara necessidade de explicação exista, é inteiramente secundária, acontece em grau limitado e é mais fraca que qualquer outra que possa sentir, além de estar sujeita a desejos e temores, e não à racionalidade (KELSEN, 1946, p. 4). Assim, a tendência ao pensamento causal está fora de questão para o homem primitivo.

Kelsen demonstra, como prova de suas constatações, a interpretação dada pelo homem primitivo à morte, muitas vezes encarada como castigo infligido por uma autoridade sobrehumana (KELSEN, 1946, p. 4). A verdade é que o homem primitivo não tem conhecimento suficiente para compreender uma relação necessária entre dois eventos. Não é a ele possível, portanto, buscar uma causa verdadeira, e, ainda que a encontrasse, não daria a ela o condão de configurar uma causa. Mais, ainda que desse, não lhe seria objeto de reflexão. A associação entre eventos pelo homem primitivo obedece a uma predisposição baseada nas emoções, ou, muitas vezes, na crença em entes sobre-humanos, mas nunca na racionalidade, na causalidade. O pensamento do homem primitivo está dominando pela idéia de retribuição, não pela lei da causalidade. 


\subsection{Prevalência do componente emocional}

A mente primitiva é essencialmente dominada pelo componente emocional, em detrimento do racional. Como ressalta Kelsen, o lado emocional é o mais antigo ou, pelo menos, o mais forte originalmente. Sendo o racional o elemento que tende ao conhecimento objetivo, e o emocional o que é determinado pelo sentimento e pela vontade, é cediço que o homem primitivo se apercebe do mundo sem que se interesse pelas relações objetivas que o regem, suas causas e efeitos, não sendo, por isso, capaz de propriamente conhecer o que lhe rodeia (KELSEN, 1946, p. 1).

Normalmente, os seres e coisas com as quais o primitivo convive lhe causam medo ou desejo, trazendo-lhe ímpeto de se afastar ou de se aproximar, sem que se preocupe em conhecê-lo.

Nas precisas palavras de Kelsen, "sobre as idéias decorrentes do componente emocional se baseiam os conceitos de valor a respeito do que é prestativo porque é desejado, do que é prejudicial porque é temido, do que é moralmente bom ou ruim porque é a expressão do interesse grupo, mais do que do indivíduo. Essas idéias não dizem respeito à explicação de fenômenos, mas sim à necessidade de reagir aos eventos naturais que tem o homem primitivo (...). Assim como a inclinação racional leva à natureza governada pelas leis da causalidade, a inclinação emocional leva à sociedade governada por normas. Para o homem civilizado, tais diversos elementos mentais são realmente dois mundos diversos, correspondentes a díspares atitudes mentais fundamentais" (KELSEN, 1946, p. 1)4. Infere-se dessa passagem que as avaliações do homem primitivo sobre a realidade estabelecem uma ordem normativa do comportamento humano.

Os melhores estudos indicam que não há razão para se supor uma real tendência ao conhecimento ou mesmo uma vontade por qualquer explicação da realidade que seja objetiva, independente do que querem os desejos ou os medos, isenta de pré-avaliações.

\footnotetext{
4 Tradução livre para o português do texto original em inglês : "upon these ideas are based concepts of value: of what is useful because desired, of what is harmful because feared, of what is morally good or bad because it is the expression of a group, rather than an individual, interest. These ideas are not concerned with explaining phenomena but with the need which primitive man feels for reacting to natural events, the justification of which action is the specific function of these ideas. Hence evaluations are expressed which establish a normative order of human behavior. Just as the rational attitude leads a nature governed by laws of causality, so the emotional attitude leads to society governed by norms. For civilized man these are indeed two different worlds, corresponding to fundamentally disparate mental attitudes".
}

Revista da Faculdade Mineira de Direito, v.13, n. 25, jan./jun. 2010 - ISSN 1808-9429. 


\title{
3.3. Ausência de curiosidade
}

O novo desperta no homem primitivo medo, não curiosidade. Sua mente, diferente da do homem civilizado, não é sensível às contradições lógicas. Não existe interesse por explicações lógicas e racionais, mas reações instintivas.

Estudos empíricos demonstram que os primitivos lidam com as contradições de suas idéias de forma completamente irracional. Podem acreditar simultaneamente em fatos absolutamente paradoxais e, se disso alertados, não parecem demonstrar qualquer inclinação para avaliá-los de forma lógica.

Kelsen demonstra que o desejo do primitivo por conhecimento é muito pouco desenvolvido e, se raramente o demonstra, fá-lo de forma totalmente vinculada à tendência "emocional-normativa".

Uma das observações mais interessantes e inquietantes de nossa pesquisa diz respeito ao fato de que as coisas existem para o "eu" primitivo somente se lhe causam alguma emoção. Como afirma Cassirer, a natureza é apresentada ao homem muito antes de ser objeto de percepção ou objeto de conhecimento (KELSEN, 1946, p. 3) ${ }^{5}$.

O filme "What the bleep do we know?", que em português recebeu o título "Quem somos nós?", dos Diretores Betsy Chasse, Mark Vicente e William Arntz, traduz bem a idéia aludida:

\begin{abstract}
O único filme que está passando no cérebro é aquele que temos a capacidade de ver. Então é possível que nossos olhos, nossas câmeras, vejam mais do que nosso cérebro tem a capacidade de projetar conscientemente? Bem, pelo modo como nosso cérebro está conectado nós só vemos o que acreditamos ser possível. Comparamos padrões que já existem dentro de nós através do condicionamento. Então uma história maravilhosa que acredito ser verdadeira é aquela de que, quando os índios, os nativos americanos das ilhas caribenhas viram os navios de Colombo se aproximando, eles não puderam vê-los, porque eram tão diferentes de qualquer coisa que já tinham visto antes. Eles não conseguiram enxergá-los. Quando a armada de Colombo desembarcou no Caribe nenhum dos nativos foi capaz de ver os navios embora eles estivessem no horizonte. A razão pela qual eles nunca viram os navios foi por não terem nenhum conhecimento em seu cérebro, nenhuma experiência de que navios grandes existiam. Então, o pajé começa a perceber que há ondulações ao longe do oceano, mas ele não vê nenhum navio. Porém começa a se perguntar o que está causando o efeito. Então, todos os dias ele vai lá e olha. E, após um período de tempo, consegue ver os navios. E, uma vez que vê os navios, ele diz para todas as outras pessoas que existem navios ao longe. E porque confiam e acreditam nele, todos os vêem também. Nós criamos a realidade. Somos máquina de produzir realidade. Criamos os efeitos da realidade o tempo todo ${ }^{6}$. (What the bleep do we know?, 2004).
\end{abstract}

5 Tradução livre para o português do texto original em inglês: "Nature, too, is presented to man in this way long before it can become the object of perception, or even the object of cognition".

6 Tradução livre para o português do texto original em inglês: "Did you know that the brain imprints what it has the ability to see? Now this is important. For example, this camera is seeing a lot more around me than what is here. Because it has no objection and no judgment. The only movie that's playing in the brain is what we have

Revista da Faculdade Mineira de Direito, v.13, n. 25, jan./jun. 2010 - ISSN 1808-9429. 
O homem primitivo não consegue ver o que não consta de sua experiência anterior ou que não lhe afete diretamente.

Instigados pela idéia trazida na obra de Recasens Siches (RECASENS SICHES, 1972) sobre o que atualmente importa ao homem, observamos a disparidade sobre o que é objeto de conhecimento para o homem primitivo e o que o é para o homem civilizado. Deparamo-nos com uma questão de extrema relevância no que diz respeito ao óbvio.

O primitivo percebe o óbvio, o que consta de sua bagagem de conhecimento, e ignora o desconhecido, extraordinário, ainda que faticamente o veja.

Por outro lado, pesquisas demonstram o desprezo desenvolvido pelo homem civilizado no que diz respeito ao que vê todo dia. Atingiu-se o ponto de não mais enxergar a realidade a qual se acostumou. Salvo os mais observadores ou altruístas, pessoas desconhecidas, garis e meninos de rua passam despercebidos pelo homem comum.

Não estava tratando do assunto quando a proferiu, mas cabe transcrever uma afirmação de Malinowski: "Está na natureza do interesse científico [para não dizer do homem civilizado], que não é senão refinada curiosidade, interessar-se mais prontamente pelo extraordinário e sensacional do que pelo normal e rotineiro (...). O estudo sistemático adota o miraculoso somente para transformá-lo em natural" (MALINOWSKI, 2003, p. 60). E temos cada vez mais coisas óbvias, não obstante de complexidade indizível.

Para que seja suficiente a ponto de interessar o homem civilizado, o objeto há de ser diferente, novo, condizente com seu espírito por vezes egoístico. Estaria então voltando a ser pouco curioso o homem?

\footnotetext{
the ability to see. So is it possible that our eyes, our camera ssee more than what our brain has the ability to counsciously project? Well, the way our brain is wired up we only see what believe is possible. We match patterns that already exist within ourselves through conditioning. So, a wonderful story that I believe is ture is that when the Indians, the Native American Indians on the Caribbean Islands saw Columbus ships approaching they couldn't see them at all, because it was so unlike anything they had ever seen before. They couldn't see it. When Columbu's armada landed in the Caribbean none of the natives were able to see the ships even though they existed on the horizon. The reason that they never saw the ships was because they had no Knowledge in their brains, no experience that clipper ships existed. So the Shamam starts to notice there are ripples out in the ocean. But he sees no ship. But he starts to wonder what is causing the effect. So every day he goes out and looks and looks and looks. And after a period of time, he's able to see the ships. And once he sees the ships he tells everybody else that ships exist out there. Because everybody trusted and believed in him, the saw them also. We create reality. We're reality producing machines. We create the effects of reality all the time".
} 


\section{REPERCUSSÕES DA MENTALIDADE PRIMITIVA SOBRE O DIREITO}

Da compreensão da ausência de consciência do eu pelo homem primitivo, causa e consequiência de como funciona a mente primitiva, decorrem importantes relações com o Direito. São estas relevantes não só pela acuidade inerente ao tema, mas, como todo estudo que se volta para o passado, pelos ensinamentos que oferece para uma maior compreensão do presente e, quiçá, melhora do futuro.

\subsection{A Responsabilização e a forma de aplicação da sanção}

A responsabilização pelos ilícitos na sociedade primitiva é intimamente ligada à forma como funciona a mente do homem primitivo.

Contra uma das bases da nossa segurança jurídica, que venera a regra de responsabilização de somente quem efetivamente tenha dado causa ao dano - muitas vezes somente se tenha incorrido em dolo ou culpa - e que se adéqua de forma receosa e relutante a excepcionais casos de responsabilidade objetiva, a responsabilização que ocorre nas sociedades primitivas nos parece realmente o que de mais primitivo pode um homem conceber. Supera-a, talvez, apenas a aplicação privada da sanção, em detrimento do monopólio do uso da força.

Os primitivos não conheciam o monopólio do uso da força por um órgão centralizado, e "quando de um conflito, havia aplicação privada da sanção. Demais, a responsabilidade era coletiva: se alguém de uma tribo agride alguém de outra tribo, responsável não é o indivíduo que agrediu, é todo o grupo que, portanto, deve ser punido. (...) ao contrário dos primitivos, na modernidade o Estado consagra a responsabilidade individual e o monopólio estatal (não privado) do uso da força. Se eu agredir minha família não será punida, e a aplicação da sanção não será efetivada pela pessoa agredida: um órgão do Estado se encarregará disso. A pessoa agredida só abre mão da aplicação da sanção porque sabe que o órgão estatal pelo menos indiciará o agressor. Chamo isso de "justo monopólio do uso da força"” (TRAVESSONI GOMES, 2003, p. 307). Ligada à ausência de percepção por parte do homem primitivo sobre a condição de homem, de ser diverso, de ser pensante, a falta de consciência de sua própria individualidade impõe que o primitivo desconheça por completo a responsabilidade individual. Efetivamente, parece-nos evidente que o homem primitivo não veja qualquer diferença entre punir, por uma lesão que sofreu o grupo ao qual pertence, um ou outro elemento qualquer do grupo que o lesou. 
O homem primitivo identifica somente a coletividade, o todo do qual faz parte, ignorando por completo sua existência individual.

A falta de noção sobre a individualidade, sob seus dois enfoques, afasta do primitivo a compreensão de que a imputação de fatos a determinada pessoa não é, por si só, a solução para o que tenha ocorrido. Sua incapacidade de reconhecer as relações de causalidade faz com que atribua responsabilidade a certa pessoa por fatos aos quais o ser humano jamais poderia dar causa, tal como a tempestades ou enchentes, ou que responsabilize por fatos realmente causados por homens uma pessoa - ou até um ente não humano - que não os realizou.

Outra idéia proeminente na sociedade primitiva é a de responsabilidade coletiva. $\mathrm{O}$ grupo é bem-aventurado ou castigado em razão dos atos que praticasse aos deuses, dos sacrifícios oferecidos ou do desprezo pelas entidades supernaturais. Não importa se alguns pautaram seus comportamentos pelo "bem" e outros pelo "mal". Pertencentes ao mesmo grupo, todos seriam castigados em virtude das iniqüidades praticadas por alguns, bem como todos seriam abençoados se a prática fosse de benevolência aos deuses.

Autonomia é conceito plenamente desconhecido pelo homem primitivo. Incapaz de perceber sua "humanidade", é inábil a reconhecer os próprios atos e o dos outros. Todos os entes são apenas parte de um todo homogêneo, não sendo possível atribuir a cada um a responsabilidade pelos atos emanados. Se o comportamento é de um do grupo, o grupo responde. Mesmo em relação aos grupos, distorce-se qualquer fundamento de responsabilização quando muitas das ações são atribuídas a deuses, instrumentos de trabalho, animais e seres inanimados. Na maior parte das vezes, punir ou gratificar algo ou alguém satisfaz a mera necessidade de provar temor aos entes sobre-humanos.

\subsection{A Consciência Coletiva}

A mentalidade do homem primitivo é totalmente determinada pela vida social. Prova disso é que as linguagens primitivas são caracterizadas pelo não desenvolvimento das possibilidades de expressão na primeira pessoa. Muitas narrativas sobre as sociedades primitivas demonstram que certas línguas não têm qualquer termo para se referir ao "eu", ou que, quando têm, servem-se à identificação do grupo, e não exclusivamente de uma pessoa.

Como demonstra Kelsen, "um sintoma particularmente impressionante da solidariedade completa do indivíduo para com o grupo é o hábito, observado em certas tribos, 
pelo qual, em caso de doenças, não apenas a pessoa doente mas também todos os membros de sua família precisam se submeter a tratamento" (KELSEN, 1946, p. 11) ${ }^{7}$.

Kelsen esclarece que, visto que o indivíduo não é nada mais que um membro de seu grupo, ele pode ser substituído por outro (KELSEN, 1946, p. 13), como mostra uma passagem sobre os índios norte-americanos: "A perda [pela morte] de um indivíduo é uma grande perda, mas uma perda que tem que ser reparada necessariamente pela reposição do indivíduo que falta por um ou vários outros indivíduos, dependendo da maior ou menor importância da pessoa que tem que ser substituída" (KELSEN, 1946, p. 13) ${ }^{8}$.

O homem primitivo é levado à atitude coletivista não só pela ausência de consciência do eu, mas também pela tendência à substancialização. As qualidades e condições, tais como a moral e a lei, são consideradas substâncias concretas, mesmo contagiosas, que impõem que o primitivo perceba-se ligado de forma efetiva ao grupo. Na consciência primitiva, a idéia de um indivíduo independente da comunidade não pode existir (KELSEN, 1946, p. 16).

Malinowski repudia a idéia "de que nas sociedades primitivas o indivíduo é completamente dominado pelo grupo - horda, clã ou tribo - e obedece às ordens da comunidade, às suas tradições, à opinião pública e a seus decretos com uma obediência servil, fascinada e submissa" (MALINOWSKI, 2003, p. 10). O autor utiliza sua experiência com tribos primitivas para sustentar as idéias de direitos individuais, caráter não social da propriedade, atos de reciprocidade e mutualidade, e não prevalência do social em detrimento do individual (MALINOWSKI, 2003).

Ele afirma que "de modo geral, as regras são seguidas, porque sua utilidade prática é reconhecida pela razão e comprovada pela experiência” (MALINOWSKI, 2003, p. 10), racionalizando de forma brusca uma mentalidade que pouco conhece os motivos racionais.

Apesar da oposição ao que expomos, o próprio Malinowski admite, em certas passagens, a força da sociedade em detrimento do indivíduo, como ao afirmar que os selvagens têm classe de regras compulsórias providas de uma força aglomeradora puramente social (MALINOWSKI, 2003).

Aos que nos parece, Malinowski utiliza artefatos argumentativos que explicam as mesmas situações de formas diversas. Por vezes, desconsidera intransigentemente a ausência

\footnotetext{
7 Tradução livre para o português do texto original em inglês: "A particularly striking symptom of the individual's complete solidarity with the group is the custom, observed among certains tribes, according to which, in case of illness, not only the sick person but also all the members of his family must undergo treatment".

8 Tradução livre para o português do texto original em inglês: "The loss [by death] of a single individual is a great loss but a loss that has to be repaired necessarily by replacing the missing individual by one or several individuals according to the greater or smaller importance of the person who has to be replaced".
} 
de individualidade, quando o que quer, na verdade, é insistir que as normas primitivas não possuem caráter místico nem são impostas por sanção sobrenatural. Para tanto, interpreta as mesmas histórias que nos levam a crer na coletivização como demonstração de traços individuais inerentes às tribos primitivas, até mesmo numa tentativa de transformar em regras aspectos excepcionais. Diante disso, preferimos e adotamos a coerência kelseniana.

\subsection{O Retributivismo}

Hans Kelsen explica que o "princípio social da retribuição" determina tanto o comportamento do primitivo sobre a natureza quanto a sua conduta em relação aos membros do seu e dos outros grupos (KELSEN, 1946, p. 49).

$\mathrm{O}$ autor explica que existe uma tendência, entre os estudiosos, à associação da "retribuição" a uma primeira emoção do homem, especialmente o instinto natural à vingança, que deve ser observado não só nos primitivos, mas também nas crianças e mesmo nos animais (KELSEN, 1946, p. 49). Kelsen critica essa visão por ser embasada no entendimento equivocado de que o comportamento do homem primitivo é mera atitude instintiva, quando, na verdade, a retribuição distingue-se, nitidamente, tanto da reação defensiva emanada do desejo de auto-preservação quanto do sentimento exclusivamente vingativo.

Percebemos que verdadeiramente existe uma inclinação do ser humano - primitivo ou civilizado - à vingança, mas não discordamos do autor. Efetivamente, o primitivo não age de forma retributiva tão-somente guiado por uma das paixões humanas que fogem à razão. Ao contrário, a retribuição é o meio pelo qual se garante que o mal sofrido seja reparado, ainda que, muitas vezes, isso sirva apenas como demonstração de temor.

Kelsen assegura que o princípio da retribuição aparece, primeiramente, ao homem primitivo, em sua forma mais drástica, a fórmula "olho por olho, dente por dente". A punição seria uma forma de obter compensação pelas injúrias, não para prevenir crimes ou com qualquer outra finalidade moderna que supostamente tenha a pena (KELSEN, 1946, p. 58).

O homem primitivo não só interpreta os fenômenos da natureza, como pauta a produção de normas de conduta, baseado no princípio da retribuição. Aliada à peculiar mentalidade primitiva, uma causa transcendente - a vontade de Deus - determina que os acontecimentos sejam vistos como prêmio ou castigo.

Guiados por reflexões que explicitam o comportamento por diversas vezes passional do homem civilizado, deparamo-nos com ocorrências mais instigantes do que a conclusão de que a racionalidade do homem civilizado não é capaz de suprimir por completo e a todo tempo sua sensibilidade. $\mathrm{O}$ homem civilizado presencia a punição do infrator para alcançar a 
retribuição pelo mal sofrido, afora o que se espera das finalidades da pena, a ameaça abstrata, a prevenção de novo crime, a ressocialização. Mas, não raras vezes, não se satisfaz e busca meios que efetivamente lhe garantam o sentimento de compensação. Muitas narrativas há de casos em que, passados anos de determinada infração, restando comprovado que a punição já não mais surtiria qualquer efeito prático, o instinto por "justiça" do homem civilizado determina que ainda assim há de se aplicar a pena.

Primitiva ou não, a intuição de que o mal causado deve sempre ser reparado persegue o homem de seus primórdios até hoje. Entretanto, é de se notar que o principal impulso que leva o homem primitivo a buscar a retribuição é a necessidade de responsabilização pelo ato. Curiosamente, percebe-se que, ao contrário, o homem civilizado tende, quase sempre, a demonstrar necessidade de vingança, de justiça, de ressarcimento do mal com o mal e do bem com o bem, indicando razões de comportamento muito mais irracionais e passionais que jamais nortearam o próprio homem primitivo, aquele regulado por seus instintos, por suas emoções.

Quando dizemos que o homem primitivo retribui o mal causado pelos seus "semelhantes", pode estar fazendo-o contra ente que, sob nossa concepção, não é sequer sujeito de direitos, ou pode até estar imputando a alguém - ou a algo - fatos naturais, desastres ou meros acidentes que julga prejudiciais. Ao primitivo pouco importa a explicação lógica e verdadeira que incessantemente busca o homem civilizado. À racionalidade do primitivo basta que haja uma resposta à infração; a necessidade é atribuir responsabilidade, não perquirir causa.

Mas, ressalte-se, o primitivo desconhece suas limitações. Não se fala em desprezar conscientemente os responsáveis reais. Fala-se em ignorar a relação de causalidade, a individualidade de cada ente humano, em buscar a responsabilização dentro do ambiente que se lhe apresenta.

O homem primitivo, na fraqueza de sua racionalidade, desloca os sentimentos a um segundo plano, buscando a retribuição por causas objetivas, ainda que inconscientemente imaginárias. O homem civilizado, essencialmente racional, busca a retribuição por causas subjetivas, conscientemente passionais, apesar de protegido pela máscara da objetividade falaciosa da finalidade das penas. 


\title{
5. HOMEM PRIMITIVO DA SOCIEDADE MODERNA OU HOMEM CIVILIZADO DA SOCIEDADE PRIMITIVA?
}

Em 21 de dezembro de 2001, A. O. Scott escreveu para o "The New York Times", relacionando os filmes "Abril Despedaçado" e "In the Bedroom":

\begin{abstract}
O filme de Field [In the Bedroom], baseado num conto de André Dubus, explora, com uma simpatia velada, o ato de vingança de um pai diante do assassinato do filho. Sua força é decorrente da atitude impensável por parte de um médico civilizado de classe média do Maine, que sucumbe ao impulso atávico de responder à violência com violência. $\mathrm{O}$ assassinato final, embora terrível, é purificador e catártico, um modo de se reparar um terrível desequilíbrio na ordem moral. (...)

"Abril Despedaçado" oferece um olhar de advertência sobre um mundo em que a violência é o princípio básico da ordem social, a regra em vez da exceção. Passado no árido sertão nordestino brasileiro, em 1910 (e baseado no livro homônimo do escritor albanês Ismail Kadaré), o filme retrata a espiral cruel da vendeta e do derramamento de sangue que consomem duas famílias rivais de plantadores de cana. Nas paredes das casas de ambas as famílias, há galerias de retratos dos mortos em molduras ovais. Velas são acesas sob os retratos dos recém-executados e suas camisas ensangüentadas são expostas ao ar livre, de acordo com um costume que se traduz em misericórdia naquele universo. O próximo assassinato terá de esperar até o sangue da camisa amarelar, dando à próxima vítima - e ao próximo assassino - um mês de trégua antes do inicio da fase seguinte do ciclo. (...)

O preço dessa luta é, como era de se esperar, devastador, mas não sem uma nota de otimismo redentor. E com isso fecha-se um círculo: "In the Bedroom" é um filme sobre um homem contemporâneo impelido pelas circunstâncias a uma visão de mundo brutalmente arcaica. "Abril Despedaçado", em contrapartida, é sobre o desejo honrado e reprimido de se viver num mundo moderno, numa região onde ainda mal se ouviu falar dele." (SCOTT, 2001).
\end{abstract}

A dualidade homem primitivo versus homem moderno parece recrudescer ou atenuar conforme o enfoque que se proponha e a que se proponha. A crítica de cinema transcrita parece ser o instrumento ideal para que encontremos em um mesmo homem o primitivismo e a civilidade.

As personagens de "Abril Despedaçado" não vivem em uma sociedade propriamente primitiva, mas nelas encontram-se traços típicos do homem primitivo, como a responsabilidade social verificada de forma clara. A pessoa indicada para receber a pena o faz para expurgar o mal praticado por um grupo inteiro, e não por ser responsabilizada por um ato que praticou. É até instintivo considerar que, entre os homens primitivos, prepondera o sentimento irracional e passional de vingança. Mas, analisando-se os fatos de forma finalística e pragmática, percebe-se a prevalência do comportamento de retribuição, com caráter objetivo e até racionalizado, transparente quase ao ponto do diálogo.

A sociedade de "In the Bedroom" é tipicamente moderna. Não se espera de um médico comportamento desvirtuado. A justiça privada, ainda que reconhecidamente justa, é considerada, em regra, uso arbitrário das próprias razões. O Estado tem competência e obrigação exclusivas de aplicar a sanção, reparando o dano sofrido. Mas o Estado não pode

Revista da Faculdade Mineira de Direito, v.13, n. 25, jan./jun. 2010 - ISSN 1808-9429. 
aplicar pena pior que a cominada, nem pode, diante da morte, restabelecer o status quo anterior. Nesse momento, o Estado é, então, insuficiente, porque insuficiente se faz a mera retribuição. Emerge o desejo, irracional, por vingança, que, paradoxalmente, chamamos sentimento mais primitivo.

\section{CONSIDERAÇÕES FINAIS}

Escreveu Wilson D. Wallis que, se o primitivo é potencialmente um homem civilizado, o homem civilizado é potencialmente um selvagem (KELSEN, 1946, p. 267) ${ }^{9}$. É possível definir bem as contradições humanas a partir da dualidade "civilizado versus primitivo".

Ao homem primitivo falta a curiosidade típica do homem civilizado. Estudos empíricos demonstram que ao primitivo só interessa o que diretamente lhe afeta, ou seja, ele só dispensa atenção a situações e objetos que possam prontamente repercutir em suas necessidades, seus medos e instintos imediatos.

O homem civilizado, por sua vez, busca significados e utilidades até mesmo em fatos e coisas que são aparentemente vazios de relevância, ao mesmo tempo que renega aquilo que, um dia, foi-lhe o mais caro.

A idéia inerente às civilizações, principalmente ocidentais, de que o homem pode explicar e transformar qualquer evento ou "matéria-prima" foge às limitações humanas de tal forma que ele passa a almejar o impossível, cada vez mais crente na máxima de que "a ficção de hoje é a ciência de amanhã”. E o que já é ciência perde importância com a rapidez de outra ciência que surge.

Do lado oposto, saltam aos olhos a tendência à inércia e a tendência coletivista do homem primitivo.

Mas o homem primitivo evoluiu e a ausência de consciência de individualidade deu lugar ao individualismo do homem civilizado. As prioridades, um dia comuns, são agora próprias e atuais, jamais futuras ou destinadas às próximas gerações. Nesse contexto, é difícil visualizar de que maneira vai evoluir o homem civilizado, a que estágio pode chegar.

Ao que chegaram os primitivos é fácil perceber. Somos todos um laboratório vivo. Um extremo levou a outro. Parece-nos que a descoberta da individualidade foi na verdade a descoberta do egoísmo. O homem renegou a consciência social para defender a autonomia e se perdeu tentando rejeitar a sociabilidade essencial a sua natureza. Era primitivo por

9 Tradução livre para o português do texto original em inglês: "if the savage is potentially a civilized man, the civilized man is potentially a savage". 
desconhecer sua individualidade, ignorar a própria importância, considerar-se substituível; evoluiu até tornar-se, uma vez mais, primitivo, isolando-se da humanidade que não mais reconhece e enganando-se ao pretender ser importante por si só.

Buchner diagnosticou o mal da humanidade e determinou o que precisava ser feito para o alcance da paz:

só no seio da humanidade e por ela é que o indivíduo atinge o seu pleno desenvolvimento; por conseguinte, o esforço deste indivíduo para a felicidade pessoal está necessariamente ligado, da maneira mais estreita, ao esforço da humanidade para o bem-estar e o progresso. Desgraçadamente, esta grande e importante verdade tem sido até agora muito desconhecida ou muito desprezada. (...) deve compreender que valeria mais ver todos os indivíduos, harmonizando os seus esforços, sustentando-se uns aos outros, tender ao mesmo fim, isto é, a sacudir o jugo das forças naturais, em vez de usarem o melhor da sua força a despedaçaremse, a explorarem-se mutua mente. Por outras palavras: em vez da luta para viver, a luta pela vida em geral; em vez do homem, a humanidade; em vez da guerra intestina, a harmonia geral; em vez da desgraça pessoal, a felicidade universal; em vez do universal ódio, o amor universal! À medida que o homem avança neste caminho, mais se afasta do seu passado bestial, da sua subordinação às forças naturais e às suas inexoráveis leis para se aproximar do desenvolvimento ideal da humanidade. Neste caminho, também o homem encontrará esse paraíso cuja visão já flutuava na imaginação dos mais antigos povos, esse paraíso que, segundo a lenda, o pecado tirou ao homem; com esta diferença todavia de que o paraíso futuro não é imaginário, mas real; que ele não se encontra no princípio, mas no fim da evolução humana; que ele não é o dom dum Deus, mas o resultado do trabalho, o ganho do homem e da humanidade. (BUCHNER: 1960, 190).

É difícil compartilhar, hoje, do otimismo do autor. Em regra, vemos um homem isolado, egoísta, preocupado demais com os próprios interesses e alheio aos problemas muito maiores dos outros homens. É até irônico pensar que o homem, originalmente, viu, antes de si, outro homem. A solidariedade está se tornando aberrante ao homem civilizado, quase tanto quanto autonomia e individualidade eram ao homem primitivo.

Atentando-se às exceções, o panorama não é muito melhor. A consciência do "eu" foi conquistada, mas perde-se em meio à loucura, ao delírio, ao desespero da multidão. As situações excepcionais de "consciência coletiva" - um dia regra - tornam-se cada vez menos raras. As torcidas de futebol e as pessoas atravessando a rua parecem inertes, seguidoras inconscientes do fluxo coletivo, sem pesar da individualidade perdida. Os terroristas assumem o desvalor de suas vidas ante um ideal sobre-humano, perdem-se como indivíduos em meio a um coletivo uno, indissociável.

Há algum tempo, questionamos: "recentemente, o mundo tem assistido, chocado, aos conflitos entre palestinos e israelenses. Em virtude disso, comumente surge a indagação se de fato a humanidade caminha rumo à paz perpétua ou se, ao contrário, está ocorrendo um retorno à violência típica do primitivismo?" (TRAVESSONI GOMES, 2003, p. 306). E 
concluímos: "Kant previu que quando todos os povos tivessem suas constituições fundadas na liberdade, o mundo tenderia à paz perpétua. Parece que estamos bem longe dela (...)" (TRAVESSONI GOMES, 2003, p. 306).

As relações tecidas entre primitivos e civilizados provocam-nos surpresas. Não nos aventamos, entretanto, ante às nossas constatações, a indicar caminhos. Não se trata de timidez ou covardia. Socorre-nos que a Filosofia do Direito preocupe-se com as perguntas muito mais que com as respostas. Nossa aparente impotência diante da realidade não nos ata as mãos. Por ausência de bagagem ou excessiva ousadia em adentrar tão intrincado tema, seria arrogância demais buscar soluções. Mas é sempre um passo. Não nos deixemos acometer pela desesperança. Não é justo que tenhamos que crer que o homem chegou até aqui para retornar ao ponto de partida.

Na singeleza das palavras de Fontana, acreditamos que "está nas nossas mãos voltar a começar o mundo de novo" (FONTANA, 1998, p. 280).

\begin{abstract}
This work intends to present an analysis of the reasons why important researchers of the primitive man conclude for the lack of ego-consciousness in the primitive mentality. The comprehension of the functioning of primitive's mind allows the understanding of its reflections over jurisprudence, what makes possible to search out for perceptivity of how this theme is able to help a better knowledge of man itself, particularly civilized man. The studies are based mainly on real narratives resulting from field research taken by ethnologists and anthropologists, under the sociological and juridical view of important authors, especially Hans Kelsen (Society and Nature). These researches take place in current tribes that haven't been civilized, keeping untouched its original qualities. It's demonstrated that, despite the empirical basis, the conclusions reached in this work fit better with the primitive man preceding any further civilization, given that they hadn't had opportunities from inherited knowledge by other generations. These studies resulted in same conclusion already achieved by Wilson Wallis, that if the primitive is potentially a civilized man, the civilized is potentially a primitive. This statement is possible because of the absence of ontological differences between minds of the primitive man and the civilized man, premise that has been taken under consideration during this whole research and that was definitely proved by logical and argumentative relations. It has been concluded, however, that this absence of absolute dualism does not prevent primitive and civilized men from having different ways to comprehend the world and process knowledge already absorved through diverse manners. These are, in fact, the reasons which make possible important conclusions linking primitivism to potential civility.
\end{abstract}

Key-words: primitive man, modern man, law, Kelsen 


\section{REFERÊNCIAS}

ABRIL Despedaçado. Direção: Walter Salles. Produção: Arthur Cohn. Intérpretes: Rodrigo Santoro; Ravi Ramos Lacerda e outros. Roteiro: Walter Salles, Sérgio Machado e Karim Aïnouz. Brasil, Suíça, França: VideoFilmes, Haut et Court, Bac Films e Dan Valley Film AG, 2001. 1 video-disco (99 min) Dolby SR/DTS e SRD: DVD, som, cor.

BUCHNER, Luís. O homem segundo a Ciência. O seu passado, o seu presente e o seu futuro ou donde Vimos? Quem somos? Para onde vamos? Tradução: Alfredo Pimenta. Porto: Lello \& Irmão, 1960. 367 p.

CHESNEAUX, Jean. Devemos fazer tábula rasa do passado? Sobre a história e os historiadores. Tradução: Marcos A. da Silva. São Paulo: Ática, 1995. 200 p.

FONTANA, Josep. História: análise do passado e projeto social. Tradução: Luiz Roncari. Bauru: EDUSC, 1998. 396 p.

FRANCO, Francisco Manoel de Mello; HOUAISS, Antônio; VILLAR, Mauro de Salles. Dicionário Houaiss da língua portuguesa. 1. ed. Rio de Janeiro: Objetiva, 2001. 2922 p.

HOUAISS, Antônio; VILLAR, Mauro de Salles. Dicionário Houaiss da língua portuguesa. Rio de Janeiro: Objetiva, 2001.

KELSEN, Hans. Society and Nature. A sociological Inquiry. London: Kegan Paul, Trench, Trubner \& CO., LTD., 1946. 391 p.

MALINOWSKI, Bronislaw. Crime e Costume na Sociedade Selvagem. Tradução: Maria Clara Corrêa Dias. São Paulo: Universidade de Brasília, 2003. 100 p.

RECASÉNS SICHES, Luis. Tratado General de Sociologia. 12. ed. Mexico: Porrua, 1972. $682 \mathrm{p}$.

SCOTT, A. O. Fantasia desafia violência em Vendeta. Disponível em: http://www.abrildespedacado.com.br/pt/entrada_pt.htm (Imprensa. Estados Unidos: Em português; The New York Times - 21/12/2001). Acesso em: 8 dez. 2008, 16:30:30.

TRAVESSONI GOMES, Alexandre Travessoni. Ética, Direito e Paz Perpétua. In: MERLE, Jean-Christophe; MOREIRA, Luiz (Org.). Direito e Legitimidade. 1. ed. Landy Editora, 2003, p. 298-308.

WHAT the bleep do we know?. Direção: William Arntz, Betsy Chasse e Mark Vicente. Produção: William Arntz e Betsy Chasse. Intérpretes: Marlee Matlin; Elaine Hendrix e outros. Roteiro: William Arntz, Betsy Chasse e Matthew Hoffman. EUA: Lord of the Wind, 2004. (109 min): NTSC: video-disco, som, cor. 